\title{
The anti-tumor effect of a polypeptide extracted from Tegillarca granosa Linnaeus on renal metastatic tumor OS-RC-2 cells
}

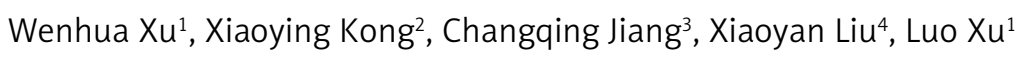

1The Medical College of Qingdao University, Qingdao, China
2Qingdao Agricultural University, Qingdao, China
${ }^{3}$ Department of Pathology, Municipal Hospital of Qingdao, Qingdao, China
${ }^{4}$ The Garrison Command Hospital of Qingdao, Qindao, China

Submitted: 22 April 2013

Accepted: 16 August 2013

Arch Med Sci 2015; 11, 4: 849-855

DOI: 10.5114/aoms.2015.53305

Copyright @ 2015 Termedia \& Banach

\author{
Corresponding author: \\ Dr. Wenhua Xu \\ Medical College \\ Qingdao University \\ 308 Ningxia Street \\ Qingdao, Shandong \\ 266003, China \\ Phone: +860532 83780075 \\ Fax: +86053288708826 \\ E-mail: xuwenhua031@126. \\ com
}

\begin{abstract}
Introduction: Renal cell carcinoma is a type of malignant tumor often diagnosed in the urinary system. The aim of this study is to evaluate the antitumor effects and mechanisms of a polypeptide, Haishengsu (TG-1), with different concentrations $(125,250,500 \mathrm{mg} / \mathrm{kg})$ on renal metastatic tumor OS-RC-2 cells.

Material and methods: We first established the renal metastatic tumor model. After being administered with TG-1, the weight of tumors was measured and the microstructural changes of renal carcinoma OS-RC-2 cells were compared using transmission electron microscopy before and after the therapy. The Ki67 expression in renal carcinoma OS-RC-2 cells was analyzed by RT-PCR and downstream signal molecule caspase- 3 was measured by Western blot assay.

Results: After treatment with different doses of TG-1, the tumor weights in the positive control group and experimental groups were smaller than those in the untreated control group, suggesting that TG-1 could effectively inhibit tumor growth in mice. The transmission electron microscopy and flow cytometry results indicated that TG-1 induces tumor cell apoptosis $(p<0.05)$. The tumor cells exhibited polymorphism changes and chromatin edge clustering. TG-1 also inhibited Ki67 expression and promoted caspase- 3 expression in the tumor significantly $(p<0.05)$.

Conclusions: TG-1 inhibits the growth of the tumor and induces apoptosis of the tumor cells by inducing caspase- 3 expression. The results provide a basis for clinical application of TG-1 in the future.
\end{abstract}

Key words: polypeptide, renal tumor OS-RC-2 cell, Ki67 mRNA, anti-tumor effect.

\section{Introduction}

Renal cell carcinoma (RCC) is a common malignant tumor of the urinary system, which represents about $2-3 \%$ of adult malignant tumors $[1,2]$. Every year about 100,000 patients die of RCC in the world. About one in three patients with RCC has metastasis [3]. Moreover, there are still $20-30 \%$ patients having metastasis after radical surgery $[4,5]$. Renal carcinoma cells are not sensitive to radiotherapy and chemotherapy. Haishengsu (TG-1) is an anti-tumor polypeptide extracted from Tegillarca 
granosa Linnaeus. Previous studies revealed that TG-1 could induce apoptosis of K562 leukemia cells and had a clear anti-tumor effect on ascitic tumor cells $[6,7]$. The combined use of TG-1 with conventional immunotherapy elevated remission rates in patients with advanced renal cell cancer and improved the physical functionality of patients [8].

Ki67, a kind of nuclear antigen which is closely related to the cell cycle, is an indicator for the proliferation of cells and has abnormal expression in many tumor cells $[9,10]$. As a DNA binding protein, Ki67 is expressed in $G_{1}, S, G_{2}$ and $M$ phases and is a key component during proliferation of tumor cells. Previous research revealed that the expression of Ki67 is closely related to the grading, staging and prognosis of many tumors. Poor prognosis is very common among patients with high expression of Ki67 [11-13]. In this study, the effects of TG-1 on renal cell carcinoma OS-RC-2 cells were studied and the Ki67 expression in renal carcinoma OS-RC-2 cells was analyzed. The differentiation and apoptosis of the OS-RC-2 cells induced by TG-1 were measured, which could provide a theoretical basis for the clinical application of TG-1.

\section{Material and methods}

\section{Cells and experimental animals}

Human renal carcinoma cells (OS-RC-2) were purchased from Shanghai Life Science Research Institute of the Chinese Academy of Sciences. SPF nude mice, male and female mice were supplied by Shanghai Slack Experimental Animals Limited Liability Company, and the mean weight of the animals was $20 \pm 3 \mathrm{~g}$. All animal experiments were conducted according to the ethical guidelines of Qingdao University.

\section{Reagents}

TG-1 was supplied by the manufacturing laboratory of Qingdao Haisheng Tumor Hospital. Newborn calf serum was purchased from Gibco (USA). Fetal calf serum and DMEM medium were purchased from Hyclone. The PR-PCR kit and Annexin V-PE/7-ADD apoptosis test kit were supplied by Promega and Becton Dickinson, respectively. Ki67 primer and the GADPH primer were synthesized by Shanghai Bioengineering Limited Company and Wuhan Boster Bioengineering Limited Company, respectively. The antibody was supplied by Beijing Zhongshan Medicine Preparation Company. FT-207 was supplied by Qilu pharmaceutical factory.

\section{Animal model}

Suspensions of mouse renal carcinoma OSRC-2 cells $\left(10^{7}\right.$ cells/l) were injected into the mouse by intraperitoneal injection. The ascitic fluid was extracted and diluted with saline, and then was injected into the enterocoella of the mouse again for another passage. The ascitic fluid was extracted again. After being centrifuged and washed by normal saline, the ascetic fluid was inoculated into the forelimb armpit (10\%/l, 0.2 $\mathrm{ml}$ per animal). The animals were then randomly divided into a negative control group, a positive control group (FT-207) and experimental groups (anti-tumor polypeptide), respectively. The experimental groups were further divided into 3 groups by administering different concentrations of TG-1 $(125 \mathrm{mg} / \mathrm{kg}, 250 \mathrm{mg} / \mathrm{kg}$ and $500 \mathrm{mg} / \mathrm{kg}$ ) respectively. There were 8 mice in each group. The animals in the positive control group were administered Tegafur (FT-207, $110 \mathrm{mg} / \mathrm{kg}$ ), and those in the negative control group were administered normal saline. Animals in all groups were administered treatments for 25 days [14].

\section{Tumor inhibitory rate}

After 25 days of administration, the tumors were isolated and weighed. Then the tumor in hibitory rate was measured. Tumor inhibitory rate $=$ (weight of tumors in negative control groupweight of tumors in experimental group)/weight of tumors in negative control group.

\section{Transmission electron microscopy (TEM)}

The tumors were cut into pieces $1.5 \mathrm{~mm} \times$ $2.0 \mathrm{~mm}$. The specimens were fixed in $40 \mathrm{~g} / \mathrm{l} \mathrm{glu}$ taraldehyde and then in $10 \mathrm{~g} / \mathrm{l}$ osmium tetroxide solution. The fixed specimens were dehydrated in a series of alcohol solutions, and then were embedded with epoxy resin. The samples were stained by uranyl acetate and lead citrate before observation.

\section{Flow cytometry}

Suspensions of mouse renal carcinoma OS-RC-2 cells were centrifuged and washed by cold PBS 2 times. The 7-ADD dye liquor $(5 \mu \mathrm{l})$ was mixed with binding buffer $(5 \mu \mathrm{l})$, and then added into the suspensions of mouse renal carcinoma OS-RC-2 cells $\left(10^{6}\right.$ cells/l). The reaction lasted for 5-15 $\mathrm{min}$ in the dark at room temperature. The mixture of binding buffer $(450 \mu \mathrm{l})$ and Annexin V-PE $(1 \mu \mathrm{l})$ was then added and kept for 5-15 min. Finally, the apoptosis of renal carcinoma OS-RC-2 cells was measured using flow cytometry at $488 \mathrm{~nm}$.

\section{Real-time polymerase chain reaction}

Total RNA of the tumor was extracted using Trizol, and the RT-PCR experiment was performed according to the requirement of the kit. The prod- 
ucts were electrophoresed in $15 \mathrm{~g} / \mathrm{l}$ Sepharose gel and scanned for absorbance with Quantity-one. The expression of the Ki67 gene was showed by $\mathrm{A}_{\text {ki67 }} / \mathrm{A}_{\mathrm{GADPH}}$. Ki67 primers were 5'-ACTTGCCTCCTAATACGCC-3' and 5'-TTACTACATCTGCCCATGA-3'; primers of the internal standard (GADPH) were 5'-ACTGCCACCCAGAAGACT-3' and 5'-GCTCAGTGTAGCCCAGGAT-3'.

\section{Immunohistochemistry}

Sections cut from the paraffin blocks were deparaffinized and treated in Tris-EDTA solution at $\mathrm{pH} 9.0$ to retrieve antigens. After peroxidase blocking reagent treatment, the anti-mouse primary antibodies were applied and incubated at $4^{\circ} \mathrm{C}$ for $12 \mathrm{~h}$. After rinsing PBS at the end of incubation, goat anti-rabbit secondary antibodies were applied. The slides were incubated at room temperature for $30 \mathrm{~min}$ before being treated with SABC chromogen at room temperature for $5 \mathrm{~min}$. The slides were incubated at room temperature for another $30 \mathrm{~min}$ before being treated with $D A B$ chromogen at room temperature for 5 min. Finally, the slides were rinsed again and stained with hematoxylin.

\section{Statistical analysis}

SPSS 17.0 software was used for data analysis and statistics. The data are shown as \pm SD. Analysis of variance was used to evaluate statistical differences between groups. The $\chi^{2}$ test was used to evaluate the difference between the enumeration data of different groups. A statistically significant difference was assumed for $p<0.05$.

\section{Results}

\section{Effects of TG-1 with different concentrations on the growth inhibition rate of tumor OS-RC-2 cells}

To determine the effect of TG-1 on the renal metastatic OS-RC-2 cells, the cells were treated with increasing dosages of TG-1 $(125 \mathrm{mg} / \mathrm{kg}$, $250 \mathrm{mg} / \mathrm{kg}$, or $500 \mathrm{mg} / \mathrm{kg}$, respectively). The cells treated with medium only served as the control. FT-207, a clinical anti-cancer drug, was used as a positive control in this study. After being treated with different doses of TG-1, the tumor weights in the FT-207 group and experimental groups (TG-1 $125 \mathrm{mg} / \mathrm{kg}$, TG-1 $250 \mathrm{mg} / \mathrm{kg}$, or TG-1 $500 \mathrm{mg} / \mathrm{kg}$ ) were smaller than those in the negative medium control group. The anti-tumor effects of TG-1 using $250 \mathrm{mg} / \mathrm{kg}$ were the best in the experimental group (Figure 1, Table I). These results suggest that TG-1 could inhibit the growth of the renal metastatic cells, with a best working concentration of $250 \mathrm{mg} / \mathrm{kg}$.

\section{TEM examination of renal carcinoma OS-RC-2 cells}

To determine the changes in cytoplasm and nucleus of the renal metastatic cells, we performed TEM examination. The cells treated with medium only served as the control group. In the control group, the tumor cells had a large volume, light electron density, oval nucleus, chromatin without edge clustering and many mitochondria (Figure 2). In the groups administered FT-207 at $250 \mathrm{mg} / \mathrm{kg}$, the volume of the tumor cells was much smaller,
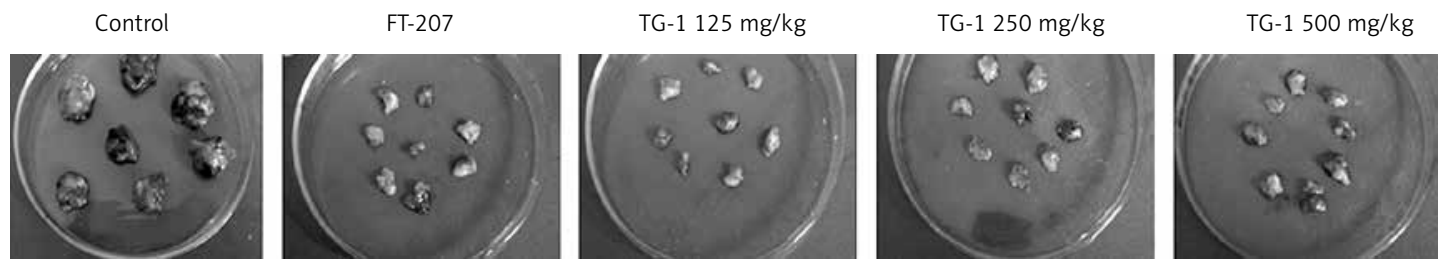

Figure 1. Tumor weight of each group with different concentrations of the polypeptide. Control, the negative control in which the cells were treated with DMEM only. The cells were treated with increasing dosages of TG-1 $(125 \mathrm{mg} / \mathrm{kg}, 250 \mathrm{mg} / \mathrm{kg}$, or $500 \mathrm{mg} / \mathrm{kg}$, respectively). FT-207, a clinical anti-cancer drug, was used as a positive control in this study. The tumor weights of animals in each group were measured

Table I. Inhibitory and apoptosis rate of renal metastatic tumor OS-RC-2 with different concentrations of the protein polypeptide $(\bar{x} \pm S D, n=8)$

\begin{tabular}{|lccc|}
\hline Groups & Tumor quality $[\mathrm{g}]$ & Tumor inhibition rates & Apoptosis rates \\
\hline Control & $1.60 \pm 0.38$ & - & $0.09 \pm 0.02$ \\
\hline FT-207 & $0.56 \pm 0.10^{\star \star}$ & 0.65 & $0.53 \pm 0.04$ \\
\hline TG-1 $(125 \mathrm{mg} / \mathrm{kg})$ & $0.88 \pm 0.15^{\star *}$ & 0.45 & $0.16 \pm 0.04^{\star}$ \\
\hline TG-1 $(250 \mathrm{mg} / \mathrm{kg})$ & $0.71 \pm 0.12^{\star \star}$ & 0.56 & $0.31 \pm 0.07^{\star *}$ \\
\hline TG-1 $(500 \mathrm{mg} / \mathrm{kg})$ & $0.76 \pm 0.08^{\star *}$ & 0.52 & $0.22 \pm 0.08^{\star}$ \\
\hline$P<0.05, p<0.01$ vs, the control group $($ cells treated with DMEM) & &
\end{tabular}

$p<0.05, p<0.01$ vs. the control group (cells treated with DMEM). 
Control

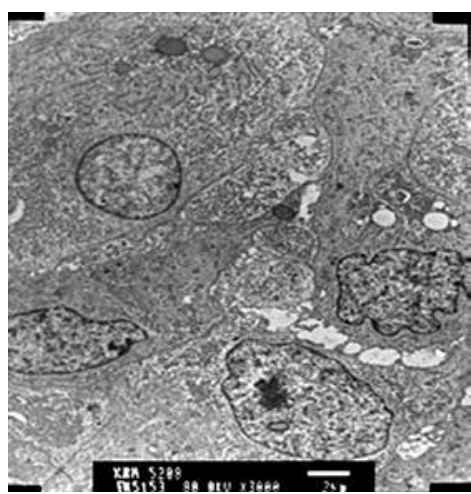

FT-207

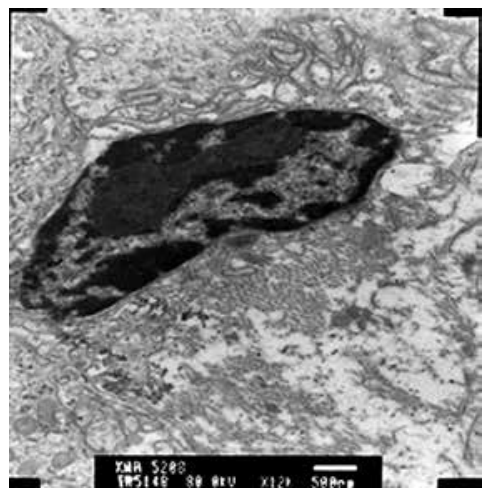

TG-1 $250 \mathrm{mg} / \mathrm{kg}$

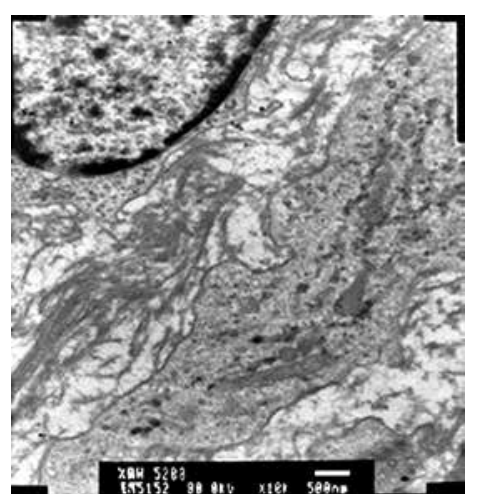

Figure 2. Apoptosis of renal carcinoma OS-RC-2 by TEM. Control, cells treated with DMEM only. FT-207, a clinical anti-cancer drug, was used as a positive control in this study. The cells were also treated with TG-1 $(250 \mathrm{mg} / \mathrm{kg})$

surrounded by a large amount of gelatinous fibers. The electron density of the cells became stronger. The nucleus was atypical and the pyknotic chromatin exhibited the edge clustering phenomenon. Some mitochondria exhibited empty bubbles. These results suggest that TG-1 could promote apoptosis of renal metastatic cells.

\section{Apoptotic effects of TG-1 with different dosages in renal metastatic cells}

To determine the apoptosis rate of TG-1 with different dosages in renal metastatic cells, we performed flow cytometry. As shown in Figure 3 and Table I, the effects of the FT-207 group and experimental groups (TG-1 125 mg/kg, TG-1 250 mg/kg, or TG-1 $500 \mathrm{mg} / \mathrm{kg}$ ) with different concentrations of TG-1 on the apoptosis of renal carcinoma OS-RC-2 cells were all significantly better than those of the negative control group (control) $(p<0.05)$, and the group administered $250 \mathrm{mg} / \mathrm{kg}$ TG-1 was the best $(p<0.01)$. These results suggest that TG-1 could promote the apoptosis of renal metastatic cells.

\section{Effects of TG-1 on expression of Ki67 mRNA}

To determine the expression of Ki67 mRNA, we performed RT-PCR to determine the changes. The expression of Ki67 mRNA in the FT-207 group and the experimental groups (TG-1 $125 \mathrm{mg} / \mathrm{kg}$, TG-1 $250 \mathrm{mg} / \mathrm{kg}$, or TG-1 $500 \mathrm{mg} / \mathrm{kg}$ ) was less than that of the negative control group (control) $(p<0.01)$, as shown in Figure $4 \mathrm{~A}$ and Table II. These results suggest that TG-1 could inhibit the expression of Ki67 mRNA.

Expression of caspase- 3 in renal carcinoma OS-RC-2 cells after treatment with TG-1

To determine the expression of caspase- 3 in the renal carcinoma OS-RC-2 cells, we performed immunohistochemistry. The positive reaction of the caspase- 3 antigen showed brown particles in the nucleus and/or cytoplasm. Compared with the negative control group (control), there was excessive expression of caspase- 3 in the experimental group using $250 \mathrm{mg} / \mathrm{kg}$ TG-1 ( $p<0.01$ ), and expression of caspase- 3 was also enhanced in the experimental groups using $125 \mathrm{mg} / \mathrm{kg}$ and $500 \mathrm{mg} / \mathrm{kg} \mathrm{TG}-1$, and the FT-207 group ( $p<0.05)$ (Figure $4 \mathrm{~B}$ and Table II). These results revealed that TG-1 could induce apoptosis of the tumor cells by inducing the expression of caspase- 3 .

\section{Discussion}

A previous study indicated that the combined use of TG-1 with conventional immunotherapy can increase the remission rates in RCC patients [8]. In this study, we first established an in vitro mouse renal metastatic tumor model. By using this animal model, we further analyzed the effects of TG-1 with increasing dosages on RCC tumors and compared the effects of TG-1 with a control FT-207. FT-207 is a currently available anti-cancer drug in clinics. By measuring the weight of tumors in animals treated with different dosages and FT-207, we found that a dose of $250 \mathrm{mg} / \mathrm{kg}$ might be the best dosage. Such a finding of the TG-1 dosage might be helpful for the following clinical trials. The reason that $500 \mathrm{mg} / \mathrm{kg}$ was less effective than $250 \mathrm{mg} / \mathrm{kg}$ might be that a high dosage such as $500 \mathrm{mg} / \mathrm{kg}$ may affect the unknown cellular signaling pathway and thus induce more side-effects. All dosages of TG-1 and FT-207 treatments resulted in more obvious effects than the medium control treatment, which suggested that our animal model and the treatments are suitable for this and future research. These results were also supported by the microstructural changes of renal carcinoma OS-RC-2 cells by using transmission electron microscopy.

Apoptosis is the independent and orderly death of cells under regulation of a series of genes, and is also known as programmed cell death (PCD). 

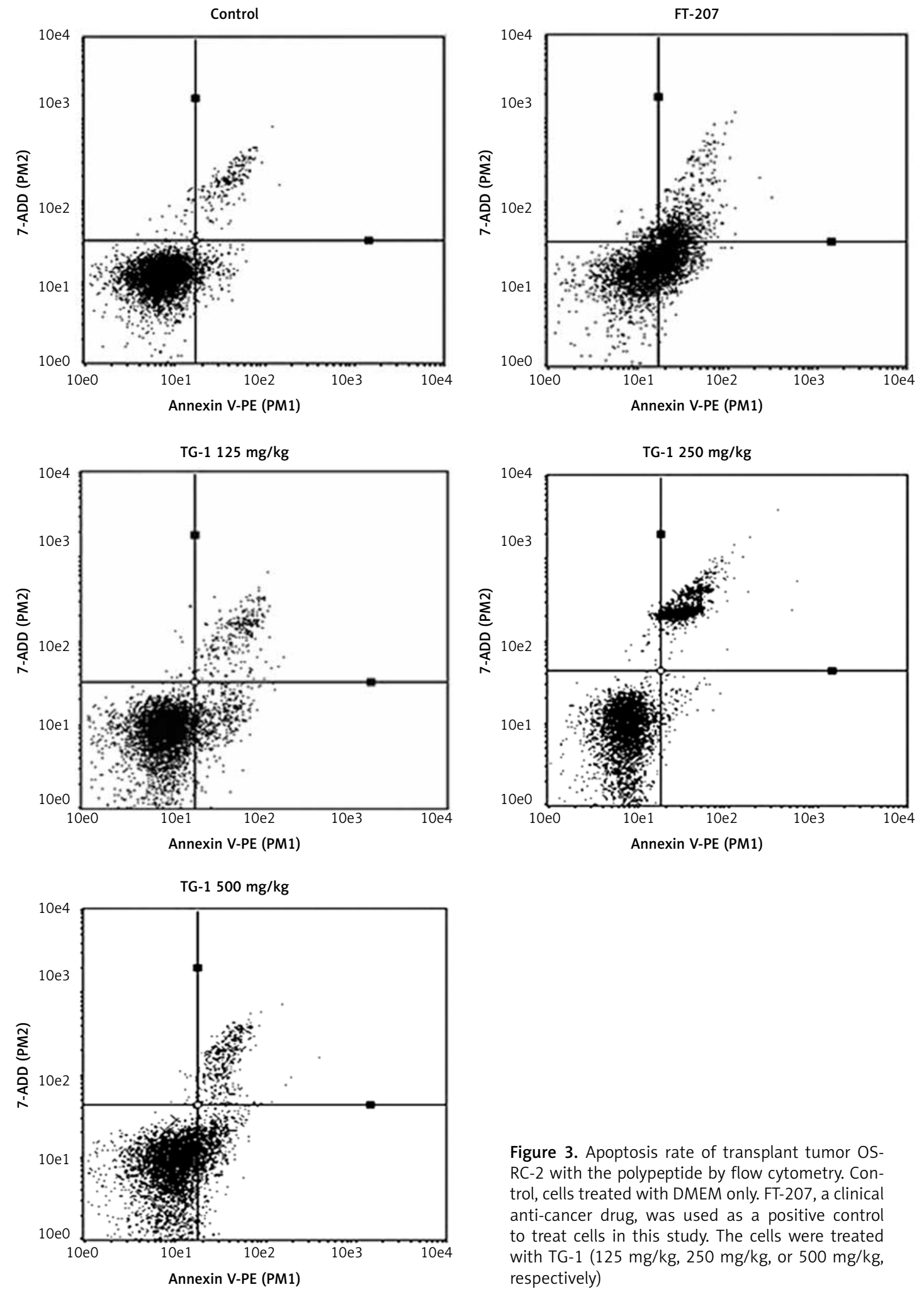

Figure 3. Apoptosis rate of transplant tumor OSRC-2 with the polypeptide by flow cytometry. Control, cells treated with DMEM only. FT-207, a clinical anti-cancer drug, was used as a positive control to treat cells in this study. The cells were treated with TG-1 (125 mg/kg, $250 \mathrm{mg} / \mathrm{kg}$, or $500 \mathrm{mg} / \mathrm{kg}$, respectively)

There are mainly two apoptotic pathways: one is to activate various caspases through extracellular signals; the other is to activate caspase through the release of activating factors in mitochondria. Activated caspases (mainly caspase-3) could degrade related proteins and then induce apoptosis

of the cells. In the caspase family, caspase-2, 8, 9 and 10 belong to the upstream, and caspase-3, 6 and 7 belong to the downstream. Caspase-3/7 $[15,16]$ could activate the common pathway of cell apoptosis by activating DNase, which digests DNA into small fragments. Caspase-3 protease 
A
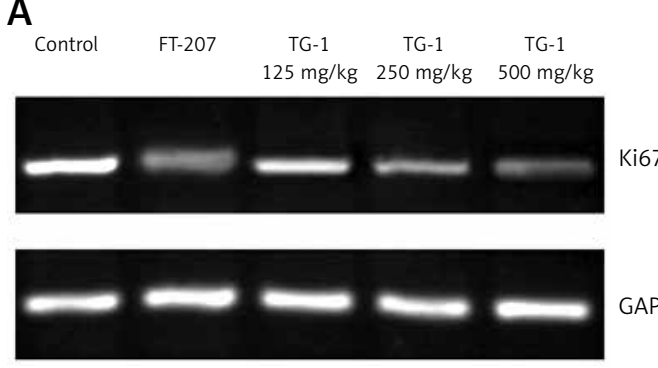

GAPDH

B

Control

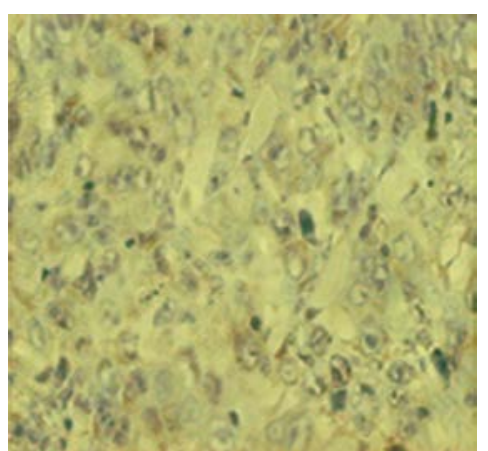

TG-1 $250 \mathrm{mg} / \mathrm{kg}$

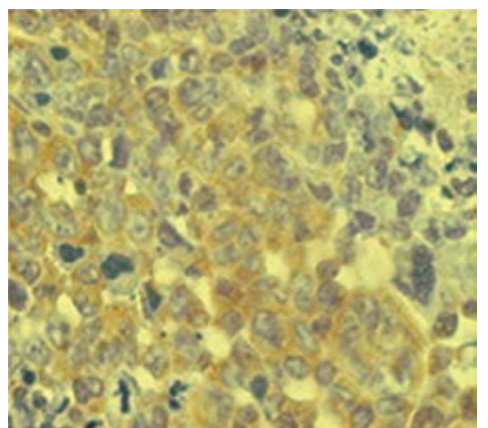

FT-207

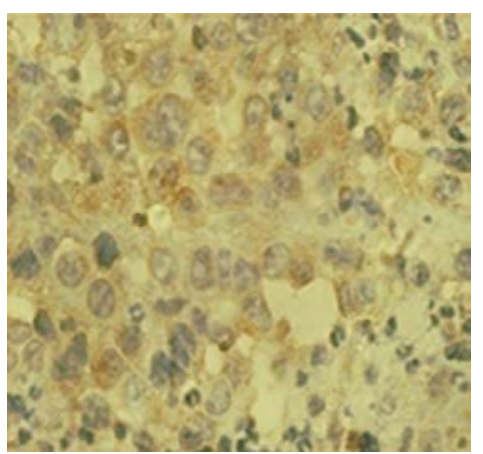

TG-1 $500 \mathrm{mg} / \mathrm{kg}$

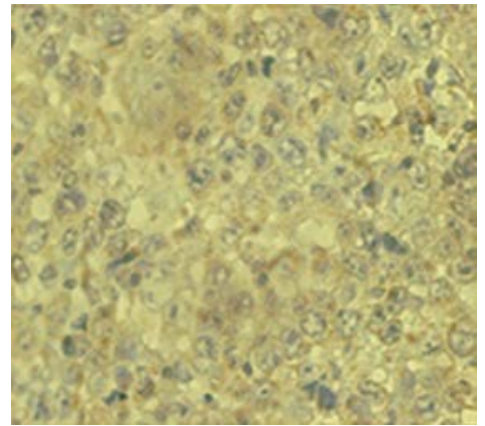

TG-1 $125 \mathrm{mg} / \mathrm{kg}$

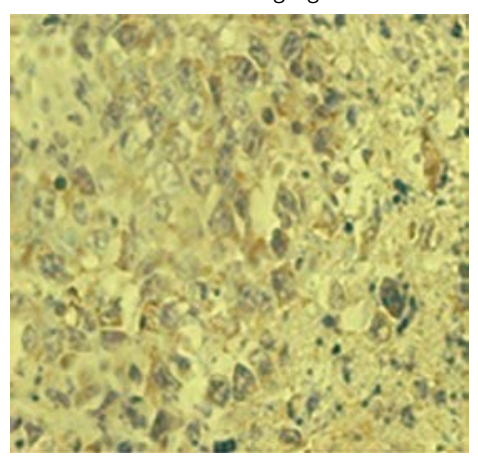

Figure 4. RT-PCR detection of Ki67 mRNA and immunohistochemical staining for caspase- 3 of the samples. A - Ki67 mRNA expression of transplant tumor OS-RC-2 treated with DMEM, FT-207, TG-1 (125 mg/kg, 250 mg/kg, or $500 \mathrm{mg} / \mathrm{kg}$, respectively). Ki67 mRNA levels were measured by PT-PCR. GAPDH served as a control. B - Immunohistochemical staining for caspase- 3 of the samples (400x). The positive reaction of the caspase- 3 antigen showed brown particles in the nucleus and/or cytoplasm

Table II. Ki67 mRNA levels and caspase-3 protein expression of transplant tumor OS-RC-2 with the protein polypeptide ( $\pm \mathrm{SD}, n=8$ )

\begin{tabular}{|lcc|}
\hline Groups & $\begin{array}{c}\text { Ki67 mRNA } \\
\text { levels }\end{array}$ & $\begin{array}{c}\text { Positive rates } \\
\text { of caspase-3 }\end{array}$ \\
\hline Control & $0.985 \pm 0.024$ & $0.396 \pm 0.324$ \\
\hline FT-207 & $0.417 \pm 0.038^{* *}$ & $0.864 \pm 0.441^{\star *}$ \\
\hline TG-1 $(125 \mathrm{mg} / \mathrm{kg})$ & $0.775 \pm 0.054^{* *}$ & $0.454 \pm 0.374^{\star}$ \\
\hline TG-1 $(250 \mathrm{mg} / \mathrm{kg})$ & $0.521 \pm 0.027^{\star *}$ & $0.639 \pm 0.425^{\star *}$ \\
\hline TG-1 $(500 \mathrm{mg} / \mathrm{kg})$ & $0.539 \pm 0.034^{* *}$ & $0.545 \pm 0.361^{*}$ \\
\hline${ }^{*} p<0.05,{ }^{* *} p<0.01$ vs. the control group. & \\
\hline
\end{tabular}

is a core enzyme of apoptosis, participating in apoptosis. Caspase- 3 protease also plays a pivotal role in the midstream and downstream of the apoptosis signaling pathways mediated by Fas.
The quantity of activated caspase- 3 is crucial to the apoptosis of the cells. Caspase- 3 could digest poly-ADP-ribose polymerase (PARP), leading to fragmentation of DNA, promoting degradation of cells and forming the apoptotic body [17-19]. Observation of the expression of caspase- 3 could help understand the apoptotic degree of the cells. In this study, in the TG-1 treatment groups, the caspase-3 protein expression was significantly increased. Obvious nuclear condensation and nuclear chromatin condensation were shown by the electron microscopy. And flow cytometry showed that TG-1 treatment group was significantly apoptosis, which was confirmed by its promotion of the expression of the caspase- 3 protein.

$\mathrm{Li}$ et al. [20] reported that the expression of Ki67 and caspase- 3 protein presents a negative correlation with each other in carcinoma of the 
vulva. The same relationship of the expression of Ki67 and caspase-3 protein in prostatic tumor was also reported [21, 22]. The appearance of the tumors is closely related with the extensive expression of the Ki67 protein and the inhibition of the caspase- 3 protein. Poor prognosis is very common among patients with high expression of Ki67 [1113]. In this study, we found that TG-1 inhibited the expression levels of Ki67 mRNA in RCC cells when compared with the FT-207 treated cells. However, the relationship between the decreased Ki67 mRNA expression and the increased caspase- 3 protein expression in the TG-1-treated cells is still not clear, which will be studied in the future. In addition to the Ki67 and caspase-3 determined in the present study, it was recently reported that some patient behavior factors such as alcohol intake and valproic acid usage also affect the risk of RCC in patients [23, 24].

In conclusion, in this study, it was found that the polypeptide TG-1 induces high expression of the caspase-3 protein and induces apoptosis of tumor cells. TG-1 also inhibited expression of the Ki67 protein, which may be related to decreased proliferation of the tumor cells. This study provides a theoretical basis for the clinical application of the anti-tumor polypeptide TG-1.

\section{Acknowledgments}

This work was supported by Qingdao Science and Technology Bureau (grant no. 10-3-31-5-NSH) and the National Natural Science Fund (grant no. 31071014).

\section{Conflict of interest}

The authors declare no conflict of interest.

\section{References}

1. Jemal A, Siegel $R, X u$ J, et al. Cancer statistics. CA Cancer J Clin 2010; 60: 277-300.

2. Xu W, Chang Z, Liu X, et al. Antitumor effects of a polypeptide isolated from Tegillarca granosa Linnaeus and the related molecular mechanism. Pak J Pharm Sci 2014; 27: 565-70.

3. Herrmann E, Bierer S, Wülfing C. Update on systemic therapies of metastatic renal cell carcinoma. World J Urol 2010; 28: 303-9.

4. Kirchner H, Strumberg D, Bahl A, et al. Patient-based strategy for systemic treatment of metastatic renal cell carcinoma. Expert Rev Anticancer Thera 2010; 10: 585-96.

5. Sun X, Huang H, Xu Z, et al. Renal cell carcinoma presents as pleural metastasis without pulmonary involvement. Chin Med J 2012; 125: 3193-4.

6. Li GY, Liu JZ, Yu XM, et al. Effect of a seashell protein Haishengsu on cell growth and expression of apoptosis genes in leukemia K562 cells. Clin Invest Med 2008; 31: E218-21.

7. Liu JZ, Chen SG, Zhang B, Wang CB, Li GY, Wang LX. Antitumor effect of the seashell protein Haishengsu on Ehrlich ascites tumor: all experimental study. J Nat Med 2009; 63: 459-62.
8. Liu JZ, Chen SG, Zhang B, et al. Effect of haishengsu as an adjunct therapy for patients with advanced renal cell cancer: a randomized and placebo-controlled clinical trial. J Altern Complement Med 2009; 15: 1127-30.

9. Wang H, Zhao K, Wang J, et al. Expression of cyclooxygenase-2, epidermal growth factor receptor and Ki67 in colorectal cancer and its significance. Shandong Med J 2008; 48: 1-2

10. Wu Z, Zhang B, Yuan Q. Expressions of cyclin E and Ki67 in carcinoma of large intestine and its clinicopathological meaning. Modern Journal of Integrated Traditional Chinese and Western Medicine 2008; 17: 4058-61.

11. Stefansson IM, Salvesen HB, Immervoll H, et al. Prognostic impact of histological grade and vascular invasion compared with tumour cell proliferation in endometrial carcinoma of endometrioid type. Histopathology 2004; 44: 472-9.

12. Bongiovanni L, Suter MM, Malatesta D, et al. Nuclear survivin expression as a potentially useful tool for the diagnosis of canine cutaneous sebaceous lesions. Vet Dermatol 2012; 23: 394-e73.

13. Gudlaugsson E, Skaland I, Janssen EA, et al. Comparison of the effect of different techniques for measurement of Ki67 proliferation on reproducibility and prognosis prediction accuracy in breast cancer. Histopathology 2012; 61: 1134-44.

14. Wang XB, Liu QH, Wang P, et al. Study of cell killing effect on renal carcinoma OS-RC-2 by ultrasound activating protoporphyrin IX. Ultrasonics 2008; 48: 135-40.

15. Luo X, Budihardjo I, Zou H, Slaughter C, Wang X. Bid a, $\mathrm{Bcl}-2$ interacting protein, mediates cytochrome $\mathrm{c}$ release from mitochondria in response to activation of cell surface death receptors. Cell I 998; 94: 481-90.

16. Galvan V, Chen S, Lu D, et al. Caspase cleavage of members of the amyloid precursor family of proteins. Neurochem 2002; 82: 283-94.

17. Ravi R, Mookergee B, Bhujwalla Z, et al. Regulation of tumor angiogenesis by $\mathrm{p} 53$-induced degradation of hypoxia-inducible factor 1alpha. Genes Dev 2000; 14: 31-44.

18. Brodsky SV, Mendelev N, Melamed M, et al. Vascular density and VEGF expression in hepatic lesions. J Gastroint Liver Dis 2007; 16: 373-7.

19. Robertson GS, Crocker SJ, Nicholson DW, et al. Neuroprotection by the inhibition of apoptosis. Brain Pathol 2000; 10: 283-92.

20. Li Y, Zhang L, Wu X. Expression and signifiance of Ki67 and caspase-3 in vulvar neoplasia. Chin J Pract Gynecol Obstetrics 2008; 24: 348-50.

21. Sun P, Jin R. Expression of Ki-67/caspase-3 cocktail double staining in prostatic adenocarcinoma. Chin J Clin Exp Pathol 2010; 26: 438-41.

22. Preusser M, Hoeftberger R, Woehrer A, et al. Prognostic value of Ki67 index in anaplastic oligodendroglial tumours: a translational study of the European Organization for Research and Treatment of Cancer Brain Tumor Group. Histopathology 2012; 60: 885-94.

23. Cheng G, Xie L. Alcohol intake and risk of renal cell carcinoma: a meta-analysis of published case-control studies. Arch Med Sci 2011; 7: 648-57.

24. Yang F, Shao Y, Yang F, et al. Valproic acid upregulates NKG2D ligand expression and enhances susceptibility of human renal carcinoma cells to NK cell-mediated cytotoxicity. Arch Med Sci 2013; 9: 323-31. 